\title{
RESEARCH
}

Open Access

\section{Repositioning: the fast track to new anti-malarial medicines?}

Julie Lotharius', Francisco Javier Gamo-Benito², Iñigo Angulo-Barturen², Julie Clark³, Michele Connelly², Santiago Ferrer-Bazaga ${ }^{2}$, Tanya Parkinson ${ }^{4}$, Pavithra Viswanath ${ }^{5}$, Balachandra Bandodkar ${ }^{5}$, Nikhil Rautela ${ }^{5}$, Sowmya Bharath ${ }^{5}$, Sandra Duffy ${ }^{6}$, Vicky M Avery ${ }^{6}$, Jörg J Möhrle ${ }^{1 *}$, R Kiplin Guy $^{3}$ and Timothy Wells ${ }^{1}$

\begin{abstract}
Background: Repositioning of existing drugs has been suggested as a fast track for developing new anti-malarial agents. The compound libraries of GlaxoSmithKline (GSK), Pfizer and AstraZeneca (AZ) comprising drugs that have undergone clinical studies in other therapeutic areas, but not achieved approval, and a set of US Food and Drug Administration (FDA)-approved drugs and other bio-actives were tested against Plasmodium falciparum blood stages.
\end{abstract}

Methods: Molecules were tested initially against erythrocytic co-cultures of $P$. falciparum to measure proliferation inhibition using one of the following methods: SYBR ${ }^{\oplus}$ dye DNA staining assay (3D7, K1 or NF54 strains); $\left.{ }^{3} \mathrm{H}\right]$ hypoxanthine radioisotope incorporation assay (3D7 and 3D7A strain); or 4',6-diamidino-2-phenylindole (DAPI) DNA imaging assay (3D7 and Dd2 strains). After review of the available clinical pharmacokinetic and safety data, selected compounds with low $\mu \mathrm{M}$ activity and a suitable clinical profile were tested in vivo either in a Plasmodium berghei four-day test or in the P. falciparum Pf3D7 $7^{0087 / N 9}$ huSCID 'humanized' mouse model.

Results: Of the compounds included in the GSK and Pfizer sets, 3.8\% (9/238) had relevant in vitro anti-malarial activity while 6/100 compounds from the AZ candidate drug library were active. In comparison, around 0.6\% $(24 / 3,800)$ of the FDA-approved drugs and other bio-actives were active. After evaluation of available clinical data, four investigational drugs, active in vitro were tested in the $P$. falciparum humanized mouse model: UK-112,214 (PAF-H1 inhibitor), CEP-701 (protein kinase inhibitor), CEP-1347 (protein kinase inhibitor), and PSC-833 (p-glycoprotein inhibitor). Only UK-112,214 showed significant efficacy against $P$. falciparum in vivo, although at high doses (ED $90131.3 \mathrm{mg} / \mathrm{kg}[95 \% \mathrm{Cl} 112.3,156.7])$, and parasitaemia was still present 96 hours after treatment commencement. Of the six actives from the AZ library, two compounds (AZ-1 and AZ-3) were marginally efficacious in vivo in a P. berghei model.

Conclusions: Repositioning of existing therapeutics in malaria is an attractive proposal. Compounds active in vitro at $\mu \mathrm{M}$ concentrations were identified. However, therapeutic concentrations may not be effectively achieved in mice or humans because of poor bio-availability and/or safety concerns. Stringent safety requirements for anti-malarial drugs, given their widespread use in children, make this a challenging area in which to reposition therapy.

Keywords: Malaria, Anti-malarial drugs, Drug repositioning, in vitro, in vivo, Plasmodium falciparum, Plasmodium berghei, Candidate drug re-profiling

\footnotetext{
* Correspondence: moehrlej@mmv.org

${ }^{1}$ Medicines for Malaria Venture (MMV), PO Box 1826, 20 rte de Pré-Bois, 1215,

Geneva 15, Switzerland

Full list of author information is available at the end of the article
} 


\section{Background}

Effective anti-malarial treatment with artemisinin-based combination therapy (ACT) has been critical for supporting and consolidating recent gains in malaria control, with reductions in the number of cases and in mortality [1]. Malaria elimination is becoming a reality for some countries [2], and strategies for global malaria eradication are now being considered [3,4]. This will require new drug regimens with improvements in cost, simplicity and efficacy against resistant strains [5]. In particular, the emergence of Plasmodium falciparum strains that are tolerant to artemisinin in the Thai-Cambodia border area is of great concern [6]. This not only has direct implications for artemisinin therapy, but promotes the selection of strains resistant to partner drugs.

New anti-malarial drugs are needed urgently [7]. Recent improvements in cell-based screening technology have led to over 20,000 new starting points in medicinal chemistry [8-10], and the great majority of these data are open access [11]. This has led to a whole series of new molecules in preclinical development [12]. For example, one series, the spiroindolones, has entered early clinical studies only five years after the initiation of screening [13].

In general, however, malaria projects take much longer than five years to go from discovery to having a clinical candidate. Sometimes this is because of technical challenges, but more often because of lack of funding or other resources and the attrition rates are high. It is clearly important to search for new approaches to make this process more efficient. An alternative approach is that of drug repositioning or repurposing. Most simply, this is taking a molecule that has been developed for one indication and showing its utility in another. Although the concept is widely discussed as an attractive drug development strategy, meaningful published data on its success rate and the factors determining that success are limited.

Starting with a molecule that has already undergone clinical trials in another indication provides several potential advantages. The clinical safety profile will be understood, and safe therapeutic doses will have been established. Importantly, human pharmacokinetic data will exist and provide some indication of whether therapeutic concentrations in the new indication can be achieved safely and maintained in patients. In addition, there are regulatory fast track processes, such as the US Food and Drug Administration (FDA) 505 (b) (2) process, where the applicant can rely on data from the studies done by others (with or without the right to reference them) to progress the compound for the new indication. This has acted as a spur to finding new activities of old molecules [14].

Programmes to identify new clinical activities of existing medicines have been conducted in many therapeutic areas, such as oncology [15] and for orphan diseases [16], where there is often an extremely high and specific unmet medical need. Approaches have also been successful in infectious disease, such as tuberculosis [17], schistosomiasis [18] and onchocerciasis [19]. In human African trypanosomiasis, fexinidazole was not so much repositioned as rediscovered following compound mining efforts of more than 700 new and existing nitroheterocycles; efficacy in animal models was initially reported in the 1980s [20,21].

In malaria, there have also been initiatives in drug repositioning. Screening a library of 2,687 compounds containing 1,937 FDA-registered medicines and 750 other molecules in clinical development identified astemizole (a histamine $\mathrm{H} 1$ antagonist) as the most promising compound, with good activity against $P$. falciparum blood stages [22]. Unfortunately, this drug was withdrawn because of side effects linked to QTc prolongation, so could not be repositioned as an anti-malarial. A smaller collection of 1,037 existing drugs was tested in an assay for activity against Plasmodium liver stages and decoquinate was identified as a potent inhibitor both in vitro and in vivo $[23,24]$. As this drug has a veterinary indication, no human safety information is available, but it remains an interesting possibility.

A further potential source of drugs for repositioning is those molecules where clinical development has been discontinued before approval. Of particular interest are drugs that did not achieve efficacy in their proposed indication even though a safe plasma exposure could be obtained in humans. However, it may be difficult to obtain information on such drugs, or gain access to physical samples of them.

In the course of screening large compound collections from pharmaceutical and biotechnology companies against the blood stages of P. falciparum [8-10], it was apparent that compounds that had progressed to clinical development were often excluded from the test set. The studies outlined in this paper aimed to specifically identify and test molecules that were not clinically available, but for which some clinical development activity had been conducted. Existing libraries of FDA-approved drugs and some selected bio-actives were also tested, with particular emphasis on antineoplastic and antiretroviral agents. Any compounds showing low micromolar activity and with a suitable pharmacokinetic and safety profile were further evaluated in vivo.

\section{Methods}

Study design

Figure 1 shows the Medicines for Malaria Venture (MMV) decision algorithm for the repositioning of drugs for the treatment of $P$. falciparum malaria $[25,26]$. In the studies reported here, compounds were tested in vitro against P. falciparum and those with significant in vitro activity 


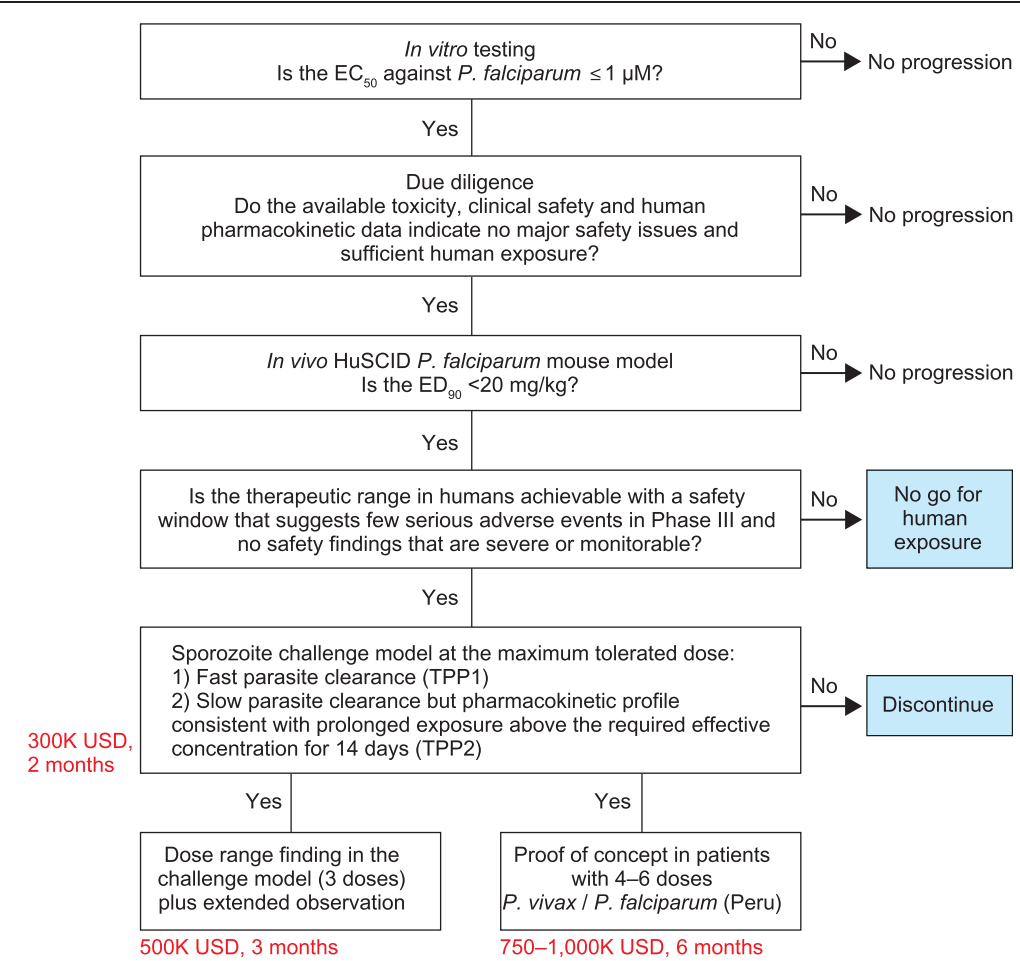

Figure 1 Medicines for Malaria Venture decision algorithm for repositioning medicines against malaria. The red text indicates the approximate amounts of money and time that are needed to conduct the studies indicated in the boxes. TPP1: Single exposure radical cure for the treatment of acute uncomplicated malaria in children and adults [25]. TPP2: Non-artemisinin-based combination therapy (NACT) for treatment of acute uncomplicated malaria in children and adults [26].

were evaluated based on the data available for toxicity, clinical safety and human pharmacokinetics (due diligence). Compounds that were active in vitro and with an acceptable safety/pharmacokinetic profile were progressed to in vivo testing. Compound testing sets and assay methods are summarized in Table 1.

\section{Compounds screened}

An initial set of around 3,500 compounds was assembled and tested by St Jude's Children's Research Hospital (SJCRH). This comprised a library of approximately 800 FDA-approved drugs registered up to the year 2008, plus about 2,700 bio-active compounds sourced from the complete Prestwick, Sigma-Lopac and Merck Sharp \& Dohme (MSD) libraries. Subsequently, a smaller set of 296 FDA-approved drugs updated for 2009 was tested as well as a small library of 47 'antiproliferative' compounds to further assess targets related to protein kinase inhibitors, antineoplastic and antiretroviral agents. Compounds were not deselected based on known toxicities in order to provide information that could inform the identification and selection of related compounds in development, which could be sourced subsequently. In total, the consolidated test set included approximately 3,800 unique compounds, excluding known anti-malarial drugs. Compounds for the SJCRH screens were sourced firstly from the SJCRH drug repository or, if not available, were obtained from commercial vendors or resynthesized. All supplied compounds were assured by the vendor as $>90 \%$ pure with quality control data provided and were verified internally at SJCRH after plating.

An initial search of the GlaxoSmithKline (GSK) clinical development pipeline on a commercially available database (Thomson Pharma) revealed around 100 compounds that had been taken into clinical development and subsequently been discontinued. Excluding those molecules that had already been screened against $P$. falciparum in the GSK discovery library [9], samples were obtained from GSK for 63 new compounds. GSK verified samples for purity and activity, and conducted the in vitro testing for this compound set.

Pfizer Inc were also approached, and offered to screen their STLAR library of 176 drugs, comprised mainly of pre-Phase III discontinued clinical candidates, though Phase III data were available for a few compounds. There were no approved drugs or active clinical candidates in the set. Pfizer provided samples verified for purity and activity. First, the compound set was tested in vitro using high-throughput screening (HTS) by Discovery Biology, Griffith University, Nathan, Australia with subsequent $\mathrm{EC}_{50}$ determination by Pfizer in-house. 
Table 1 Summary of compounds tested, in vitro screening methods, and results

\begin{tabular}{|c|c|c|c|c|c|}
\hline $\begin{array}{l}\text { Number of } \\
\text { compounds }\end{array}$ & Source & $\begin{array}{l}\text { In vitro } \\
\text { testing by: }\end{array}$ & In vitro testing method & No. hits (\%) & $\begin{array}{l}\text { No. tested } \\
\text { in vivo* } \\
\end{array}$ \\
\hline \multirow[t]{4}{*}{$\sim 3,800$} & - 800 FDA-approved drugs (2008) & SJCRH & - SYBR ${ }^{\oplus}$ dye DNA staining assay & $24(0.6)$ & 1 \\
\hline & $\begin{array}{l}\text {-2,700 bio-actives (Prestwick, } \\
\text { Sigma-Lopac, and MSD) }\end{array}$ & & - P. falciparum 3D7 and $\mathrm{K} 1$ & & \\
\hline & • 296 FDA-approved drugs (2009) & & & & \\
\hline & - 47 'anti-proliferative' compounds & & & & \\
\hline \multirow[t]{2}{*}{63} & GSK discontinued clinical candidates & GSK & $\begin{array}{l}\text { - Whole-cell }\left[{ }^{3} \mathrm{H}\right] \text { hypoxanthine radioisotope } \\
\text { incorporation }\end{array}$ & $4(6.4)$ & 0 \\
\hline & & & - P. falciparum 3D7A & & \\
\hline \multirow[t]{2}{*}{176} & $\begin{array}{l}\text { Pfizer STLAR library of discontinued } \\
\text { clinical candidates }\end{array}$ & Discovery biology & $\begin{array}{l}\text { - HTS screen using DAPI DNA imaging } \\
\text { assay with P. falciparum 3D7 and Dd2 }\end{array}$ & $5(2.8)$ & 1 \\
\hline & & Pfizer & $\begin{array}{l}\text { - } \mathrm{EC}_{50} \text { determined using } \mathrm{SYBR}^{\oplus} \text { I dye DNA } \\
\text { staining assay with } P \text {. falciparum 3D7 and K1 }\end{array}$ & & \\
\hline \multirow[t]{2}{*}{100} & AstraZeneca discontinued clinical & AstraZeneca & - SYBR I dye DNA staining assay & $6(6.0)$ & 2 \\
\hline & & & - P. falciparum NF54 & & \\
\hline
\end{tabular}

SJCRH, St Jude's Children's Research Hospital; FDA, Food and Drug Administration; GSK, GlaxoSmithKline; HTS, high-throughput screening; DAPI, 4',6-diamidino-2-phenylindole.

*Two additional compounds were sourced for in vivo testing, one each from Novartis and Cephalon Inc. In vivo testing was performed only on those compounds that had an acceptable clinical toxicity/safety/pharmacokinetic profile (or no clinical data). Except for AstraZeneca compounds, which were tested in house, all in vivo testing was performed by GlaxoSmithKline.

AstraZeneca (AZ) identified a set of 100 candidate drugs from other therapeutic areas for testing against $P$. falciparum. All 100 candidates had been discontinued for the original indication, and Phase I/II data were available for several compounds. AZ verified the samples for purity and conducted in vitro and in vivo testing for the compounds.

None of the test sets described above was prescreened for pharmacokinetics/safety but included in their entirety. This was because identification of any active compound could also have led to testing of related follow-up compounds that did not reach clinical testing (and so would not have been included in the initial test set).

\section{In vitro screening assays}

More detailed information on the in vitro methods is provided in Additional file 1.

SJCRH used the $\mathrm{SYBR}^{\circ}$ I dye DNA staining assay, which measures proliferation of $P$. falciparum in human erythrocytes [27]. Plasmodium falciparum strains 3D7 (chloroquine-sensitive) and $\mathrm{K} 1$ (chloroquine-resistant) (American Type Culture Collection [ATCC], Manassas, VA, USA) were maintained using established methods [28]. The assay method is as previously described [29]. Tests were run in triplicate in two independent runs to generate ten-point, dose-response curves to determine the half maximal effective concentration $\left(\mathrm{EC}_{50}\right)$ against the 3D7 and K1 P. falciparum strains for each drug. $\mathrm{EC}_{50}$ values were calculated with the robust investigation of screening experiments (RISE) algorithm with a fourparameter logistic equation. $\mathrm{EC}_{50}$ values of $<1 \mu \mathrm{M}$ were considered significant.
GSK Tres Cantos used a whole-cell $\left[{ }^{3} \mathrm{H}\right]$ hypoxanthine radioisotope incorporation assay to determine per cent parasite inhibition at 48 hours and 96 hours [30,31]. Plasmodium falciparum 3D7A strain (Malaria Research and Reference Reagent Resource Center MR4; [32]) was maintained as described previously [31]. Parasite growth inhibition assays and $\mathrm{EC}_{50}$ determination were carried out following standard methods [31]. Three independent experiments were conducted for each time duration and test compound. Inactive and active controls were also included. Parasite inhibition of $\geq 50 \%$ at 48 hours relative to non-treated parasitized controls was considered significant.

For the Pfizer STLAR set, initial HTS was performed by Discovery Biology, Griffith University, Australia using a 4',6-diamidino-2-phenylindole (DAPI) DNA imaging assay [33]. Plasmodium falciparum 3D7 and the Dd2 clone, which has a high propensity to acquire drug resistance were maintained using standard methods with some adaptations [28,33]. Inhibition values of treated wells were calculated relative to the minimum and maximum inhibition controls [33]. Inhibition of $\geq 50 \%$ at a concentration of $0.784 \mu \mathrm{M}$ was considered significant. Following the HTS findings, $\mathrm{EC}_{50}$ values were determined for a subset of active compounds by Pfizer using a SYBR ${ }^{\circ}$ I dye DNA staining assay, similar to that described above for SJCRH, using P. falciparum 3D7 and K1 (both from David Baker, LSHTM). Per cent antimalarial activity was calculated relative to the minimum and maximum controls for each of the 11 drug concentrations and $\mathrm{EC}_{50}$ values determined from the resulting data plot. 
AZ also used a $\mathrm{SYBR}^{\odot} \mathrm{I} \mathrm{EC}_{50}$ determination assay, but with P. falciparum NF54 (MRA-1000, MR4, ATCC, Manassas, VA, USA). The per cent inhibition with respect to the control was plotted against the logarithm of the drug concentration. The curve was fitted by nonlinear regression using the sigmoidal dose-response (variable slope) formula to yield the concentration-response curves. The concentration at which $50 \%$ inhibition was observed was taken as the $\mathrm{EC}_{50}$ value of the compound. A cytotoxicity assay was also performed by AZ, using the human hepatoma Hep G2 cell line and the per cent inhibition and $\mathrm{EC}_{50}$ values were calculated as described for P. falciparum.

For those compounds showing in vitro activity in any of the above tests, the available published and unpublished toxicity, clinical safety and human pharmacokinetic data were reviewed (due diligence).

\section{In vivo assays}

Compounds that showed promising activity in vitro and that had an acceptable toxicity/safety/pharmacokinetic profile were progressed to in vivo testing. For the AZ compound set, a Plasmodium berghei four-day suppression test was used. For all other compound sets, activity against $P$. falciparum in the huSCID mouse was determined (as described below). Animal experiments complied with all national and European Union laws, guidelines and codes of conduct for animal care and research use.

\section{Plasmodium berghei four-day suppression test}

AZ compounds were tested by the company for in vivo efficacy in a standard four-day suppression test using the rodent malaria parasite $P$. berghei [34]. All animal experimentation protocols were approved by the Institutional Animal Ethics Committee registered with the Government of India (Registration No: 5/1999/CPCSEA). Adult male BALB/c mice (purchased from RCC Laboratories, Hyderabad, India) were used for efficacy studies. Animals were randomly distributed to cages quarantined for one week with veterinary examination and then taken into experimentation. Feed and water were given ad libitum. Briefly, male BALB/c mice were infected intraperitoneally with $2 \times 10^{7}$ infected erythrocytes on day 0 . Test compounds were administered orally at a volume of $10 \mathrm{~mL} / \mathrm{kg}$ as once (UID) or twice daily (BID) doses every 24 hours for four days. On day 3, per cent parasitaemia was estimated microscopically from a Giemsa-stained blood smear. The effect of the test compound on parasite growth was calculated as the difference between the mean value of the control group (taken as 100\%) and those of the experimental group and expressed as per cent reduction. Reference anti-malarial compounds (chloroquine and artemisinin) were used as positive controls and the results obtained matched those published in the literature.
Pharmacokinetics were analysed in healthy as well as infected mice. Data from healthy mice were used for designing the dosing regimen for the efficacy studies. In infected mice, pharmacokinetics was carried out on day 2 of compound administration. One mouse per time point was sampled according to the fast mouse pharmacokinetic protocol [35].

\section{Plasmodium falciparum huSCID mouse model}

In vivo testing using this model was performed by GSK at Tres Cantos, against $P$. falciparum 3D7 (in vivo strain Pf3D $7^{\text {0087/N9 }}$ generated by GSK using Pf3D7 obtained from Eduardo Dei-Cas, Institute Pasteur, Lille, France [36]) growing in peripheral blood of female NOD-scid $I L-2 R \gamma^{\text {null }}$ mice engrafted with human erythrocytes, i e, a 'humanized' mouse model, following published protocols $[36,37]$. Briefly, animals were infected intravenously with $20 \times 10^{6}$ infected erythrocytes on day 0 . Test compounds were administered orally at a volume of $20 \mathrm{~mL} / \mathrm{kg}$ or subcutaneously $(10 \mathrm{~mL} / \mathrm{kg})$ in an appropriate inactive vehicle. Dosing was initiated at the maximum tolerated dose in mice on day 3 after infection and continued once daily for four days. Each experimental group was $n=3$ mice unless otherwise stated. Control animals received vehicle only and a quality control assay used chloroquine at target doses of $3 \mathrm{mg} / \mathrm{kg}$ and $7 \mathrm{mg} / \mathrm{kg}$. Venous blood samples for parasitology $(2 \mu \mathrm{L})$ were taken at days 3,5 , and 7 after infection. Anti-malarial efficacy was assessed using a standard four-day test (i e, at day 7) and blood parasitaemia was measured by fluorescence-activated cell sorting (FACS) analysis [38]. The limit of detection (per cent of $P$. falciparum) was $0.01 \%$. The number of parasites $\times 10^{6}$ cells was recorded and data were analysed by non-linear fitting to a logistic equation of $\log _{10}$ (per cent parasitaemia at day 7 after infection) versus the dose level administered.

Per cent parasitaemia at day 7 after infection in treated versus control animals was analysed using a one factor ANOVA with Tukey's post-test analysis. If there was a significant difference $(P<.05)$ then the $\mathrm{ED}_{50}$ was calculated as the dose in $\mathrm{mg} / \mathrm{kg}$ that reduced parasitaemia at day 7 after infection by $50 \%$ with respect to vehicletreated mice. $\mathrm{ED}_{90}$ was calculated similarly. Analysis was performed using WinNonlin 5.2 and GraphPad Prism 5.0.

The pharmacokinetics of compounds after oral administration was determined concurrently in the same mice used for the therapeutic efficacy assay. Samples were taken at $0.25,0.5,1,3,6,8$, and 24 hours after the first dose. Compound levels were measured in $25 \mu \mathrm{L}$ blood samples that were mixed with $25 \mu \mathrm{L}$ of saponin $(0.1 \%$ in water) and processed under standard liquid-liquid extraction conditions [39]. Pharmacokinetic parameters were calculated using WinNonlin 5.2 non-compartmental analysis. The data for the exposure of the drug in blood 
(area under the curve, AUC) after the first oral administration and parasitaemia at day 7 were fitted to a logistic function to predict the exposure necessary to inhibit parasitaemia at day 7 after infection in compound-treated mice by $90 \%$ with respect to vehicle-treated mice ( $\left.\mathrm{AUC}_{\mathrm{ED} 90}\right)$.

\section{Results}

\section{Screening}

At SJCRH, screening of approximately 3,800 FDAapproved drugs and other bio-actives identified 24 compounds with $\mathrm{EC}_{50}$ values $<1 \mu \mathrm{M}$ (Table 2). Of these, 19 had known pharmacokinetic and/or safety profiles that were considered unsuitable for development as an oral anti-malarial drug. Of the other compounds, two are available only for topical/external use (dequalinium, demecarium); pravastatin cannot be used in pregnancy; and sulphamerazine is a sulphonamide - a class of molecule that has already yielded anti-malarial drugs, although $P$. falciparum has developed resistance to the compounds that are used clinically. Lestaurtinib (CEP-701) is a protein kinase inhibitor in development by Cephalon Inc for acute myelogenous leukaemia and myeloproliferative disorders. Clinical information on this compound was limited at the time of the study and protein kinase inhibitors have been suggested as an important target in malaria $[9,40,41]$. Thus, only lestaurtinib was progressed to the P. falciparum HuSCID mouse model. These results mirrored those previously reported by this group [42].

In the GSK discontinued drugs set, 6.4\% (4/63) of compounds tested showed activity greater than 50\% inhibition at a concentration of $2 \mu \mathrm{M}$ in the $\left[{ }^{3} \mathrm{H}\right]$ hypoxanthine incorporation assay at 48 hours; $\mathrm{IC}_{50}$ values are shown in Table 3. Upon further evaluation, these four compounds were not progressed for the following reasons. Piritrexim is a dihydrofolate reductase inhibitor and lurtotecan a topoisomerase I inhibitor and neither

Table 2 Most active compounds tested by St Jude's Children's Research Hospital

\begin{tabular}{|c|c|c|c|}
\hline Compound & Class (therapeutic area) & $\mathrm{EC}_{50} 3 \mathrm{D} 7(\mu \mathrm{M})$ & $\mathrm{EC}_{50} \mathrm{~K} 1(\mu \mathrm{M})$ \\
\hline Methylene blue & Nitric oxide/guanylate cyclase inhibitor (various) & $<0.0003(\mathrm{NA})$ & $<0.0003$ (NA) \\
\hline Dactinomycin & Nucleoside reverse transcriptase inhibitor (oncology) & $0.0009(0,0.13)$ & $0.001(0.0003,0.006)$ \\
\hline Sulfamerazine & Dihydrofolate synthetase inhibitor (anti-infective) & $0.01(0.01,0.01)$ & $0.01(0.01,0.01)$ \\
\hline Methotrexate & Dihydrofolate reductase inhibitor (oncology) & $0.01(0.009,0.01)$ & $0.02(0.01,0.02)$ \\
\hline Bortezomib & Proteasome inhibitor (oncology) & $0.02(0.01,0.04)$ & $0.08(0.07,0.09)$ \\
\hline Thiothixene & Post-synaptic receptor agonist ${ }^{\mathrm{a}}$ (anti-psychotic) & $0.04(0,233.71)$ & $0.02(0.01,0.05)$ \\
\hline Dequalinium & Anti-septic & $0.06(0.002,1.53)$ & $0.06(0.03,0.12)$ \\
\hline Doxorubicin & Topoisomerase II inhibitor, DNA intercalating agent (oncology) & $0.21(0.16,0.27)$ & $0.20(0.14,0.30)$ \\
\hline Pentamidine & Inhibition of DNA, RNA, phospholipid and protein synthesis ${ }^{\mathrm{b}}$ (anti-infective) & $0.22(0.18,0.27)$ & $0.05(0.04,0.06)$ \\
\hline Bosutinib & Tyrosine kinase inhibitor (oncology) & $0.22(0.016,3.11)$ & $0.65(0.36,1.19)$ \\
\hline Aminopterin & Dihydrofolate reductase inhibitor (oncology) & $0.32(0.30,0.33)$ & $1.25(1.11,1.41)$ \\
\hline Midostaurin & Multi-kinase inhibitor (oncology) & $0.35(0.17,0.71)$ & $0.15(0.13,0.17)$ \\
\hline Lestaurtinib & FMS-like tyrosine kinase 3 inhibitor (oncology) & $0.49(0.28,0.84)$ & $0.34(0.29,0.41)$ \\
\hline Demecarium & Cholinesterase inhibitor (ophthalmology) & $0.51(0.45,0.57)$ & $0.30(0.26,0.36)$ \\
\hline Cyproterone & Steroidal anti-androgen (oncology) & $0.56(0.54,0.58)$ & $0.89(0,1501.50)$ \\
\hline Lapatinib & Tyrosine kinase inhibitor (oncology) & $0.56(0.39,0.80)$ & $>7.37(\mathrm{NA})$ \\
\hline Pimozide & Dopamine receptor blocker (anti-psychotic) & $0.70(0.44,1.11)$ & $>12.76(\mathrm{NA})$ \\
\hline Pravastatin & HMG-CoA reductase inhibitor (anti-cholesterol) & $0.75(0.51,1.09)$ & $0.12(0.10,0.15)$ \\
\hline Dipyrone & NSAID ${ }^{b}$ (pain) & $0.84(0.71,0.98)$ & $0.50(0.21,1.16)$ \\
\hline Mitomycin & Inhibition of DNA synthesis (oncology) & $0.97(0.81,1.17)$ & $0.51(0.45,0.57)$ \\
\hline Propafenone & Sodium channel modulator (cardiology) & $1.22(0.58,2.55)$ & $0.33(0.31,0.34)$ \\
\hline Cyclosporin A & Immune suppressant (oncology) & $1.23(1.06,1.44)$ & $0.87(0.62,1.23)$ \\
\hline Vorinostat & Histone deacetylase inhibitor (oncology) & $1.47(1.17,1.84)$ & $0.84(0.76,0.93)$ \\
\hline Sorafenib & Multi-kinase inhibitor (oncology) & $2.71(2.4,3.1)$ & $0.88(0.7,1.1)$ \\
\hline
\end{tabular}

$\mathrm{NA}$, not available. $\mathrm{EC}_{50}$ values are shown as mean $(95 \% \mathrm{Cl})$. Compounds with an $\mathrm{EC}_{50}<1 \mu \mathrm{M}$ against either $P$. falciparum strain are shown. Relevant results from all compound sets tested at SJCRH are shown. Where compounds were duplicated across the consolidated test set, the results with the most potent in vitro activity are shown. Known anti-malarial drugs have been excluded.

${ }^{a}$ Agonist of dopaminergic-receptors, serotonergic-receptors, histaminergic-receptors, alpha1/alpha2-receptors, and muscarinic (cholinergic) M1/M2-receptors. ${ }^{b}$ Mechanism unknown.

SYBR ${ }^{\oplus}$ fluorescence assay for activity against $P$. falciparum strains 3D7 and K1. 
Table 3 Most active compounds in vitro from the GlaxoSmithKline discontinued drugs compound set

\begin{tabular}{llr}
\hline Compound & Class (therapeutic area) & $\mathbf{I C}_{\mathbf{5 0}} \boldsymbol{\mu M}$ \\
\hline Piritrexim & Dihydrofolate reductase inhibitor (oncology) & $0.011 \pm 0.001$ \\
SB-435495 & Phospholipase A2-inhibitor (anti-infective/anti-inflammatory) & $1.126 \pm 0.146$ \\
Lurtotecan & Topoisomerase I inhibitor (oncology) & $0.191 \pm 0.062$ \\
GSK202405 & Muscarinic receptor agonist (asthma) & $1.582 \pm 0.206$ \\
\hline
\end{tabular}

Values are mean of three independent measures.

Study performed by GlaxoSmithKline.

$1 \mathrm{C}_{50}$ determination against $P$. falciparum 3D7A strain using $\left[{ }^{3} \mathrm{H}\right]$ hypoxanthine incorporation assay.

molecule demonstrated a significant potential therapeutic window between inhibition of the parasite and inhibition of tumor-derived cell lines. GSK202405, a muscarinic receptor agonist, is delivered via oral inhaler and has limited oral availability. SB-435495 is a phospholipase A2-inhibitor of the pyrimidone class. Previous work with this series resulted in the clinical anti-malarial candidate GSK-932121, which was stopped in clinical development because of adverse events linked to human mitochondrial respiration. SB-435495 was, therefore, not continued because of a poor human/parasite selectivity window and, after $\mathrm{EC}_{50}$ determination, its in vitro activity was borderline $(1.06 \mu \mathrm{M})$.

For the Pfizer STLAR set, the initial HTS reported $>50 \%$ activity against $P$. falciparum $3 \mathrm{D} 7$ and $\mathrm{Dd} 2$ at the $0.784 \mu \mathrm{M}$ concentration for $1.7 \%(3 / 176)$ of compounds, with $13.6 \%(24 / 176)$ having activity $\geq 90 \%$ at a concentration of $7.84 \mu \mathrm{M}$. Further evaluation of 13 of the more active compounds, identified five with $\mathrm{EC}_{50}$ values $<1 \mu \mathrm{M}$ against either $P$. falciparum 3D7 or K1 (Table 4). UK112,214 is a dual platelet activating factor receptor/histamine H1 (PAF-H1) receptor antagonist and was selected for in vivo studies in the P. falciparum mouse model. The other four compounds were not progressed for the following reasons (unpublished data provided by Pfizer Inc): CP-631992 is a neuropeptide Y5 receptor antagonist discontinued because of unfavourable animal toxicity findings; CE-245677 is a TIE2 tyrosine kinase inhibitor with reports of significant central nervous system adverse events at human plasma levels of $\sim 1.5 \mu \mathrm{M}$; CJ-0231112 is a bradykinin B2 receptor antagonist and was rejected based on drug stability issues and the effect of food on absorption; and AG-024322, a CDK1/2/4/5 inhibitor, was known to have a narrow therapeutic window in mouse cancer models and demonstrated poor tolerability in Phase I studies.

For the AZ set, 6/100 compounds had an $\mathrm{EC}_{50} \leq 1 \mu \mathrm{M}$ (Table 5). All six compounds originated from oncology programmes, mainly targeting human kinases. Of these six compounds, AZ-4 targeting CDK2 and AZ-5 targeting aurora kinase were not progressed further because of toxicity concerns with these targets incompatible with an anti-malarial therapy, specifically the essential role of CDK2 in maintaining genomic stability in mammals and myelosuppression associated with aurora kinase inhibition $[43,44]$. AZ-6 was not progressed because of poor selectivity with respect to HepG2 cytotoxicity. AZ-1 and AZ-2 are very closely related structurally. AZ-1 targets the Trk1 potassium transporter and AZ-2 targets JAK2, though both compounds have potential cardiovascular issues via hERG regulation. AZ-3 emerged from an oncology programme targeting human farnesyl transferase. AZ-1 and AZ-3 were further investigated for efficacy against $P$. berghei with the aim that if the compounds showed efficacy, they could be considered as starting points for a lead optimization programme. Pharmacokinetic studies guided the selection of the 100 or $200 \mathrm{mg} / \mathrm{kg}$ BID dose used in the in vivo experiments. Oral aminobenzotriazole $100 \mathrm{mg} / \mathrm{kg}$ was administered to inactivate cytochrome P450 metabolism and increase drug bioavailability. However, both compounds were only marginally efficacious (50-60\% inhibition) at high doses (100-200 mg/kg BID) (Figure 2). The lack of convincing efficacy even at high doses coupled with concerns regarding target selectivity and safety led to a halt in the further investigation of these compounds.

Table 4 Most active compounds in vitro from the Pfizer STLAR library

\begin{tabular}{|c|c|c|c|}
\hline Compound & Class (therapeutic area) & $\mathrm{EC}_{50} 3 \mathrm{D} 7(\mu \mathrm{M})$ & $\mathrm{EC}_{50} \mathrm{~K} 1(\mu \mathrm{M})$ \\
\hline UK-112,214 & Dual platelet activating factor/histamine $\mathrm{H} 1$ receptor antagonist (allergic rhinitis) & $0.55(0.45,0.65)$ & $0.6(\mathrm{NA})$ \\
\hline CP-631992 & Neuropeptide Y5 receptor antagonist (obesity) & $0.7(\mathrm{NA})$ & $0.40(0.2,0.6)$ \\
\hline CE-245677 & TIE2 tyrosine kinase inhibitor (oncology) & $1.1(\mathrm{NA})$ & $0.8(\mathrm{NA})$ \\
\hline CJ-0231112 & Bradykinin B2 receptor antagonist (pain) & $0.65(0.36,0.94)$ & $0.4(\mathrm{NA})$ \\
\hline AG-024322 & CDK1/2/4/5 inhibitor (oncology) & $0.7(0.11,1.29)$ & $0.4(\mathrm{NA})$ \\
\hline
\end{tabular}

$\mathrm{NA}$, not available. $\mathrm{EC}_{50}$ values are shown as mean $(95 \% \mathrm{Cl})$. Compounds with an $\mathrm{EC}_{50}<1 \mu \mathrm{M}$ against either $P$. falciparum strain are shown. 
Table 5 Most active compounds in vitro from the AstraZeneca discontinued drugs compound set

\begin{tabular}{lllll}
\hline Compound & Target & $\begin{array}{l}P f \mathrm{EC}_{50} \\
(\boldsymbol{\mu} \mathrm{M})\end{array}$ & $\begin{array}{l}\text { HepG2 } \\
\mathrm{EC}_{\mathbf{5 0}}(\boldsymbol{\mu} \mathrm{M})\end{array}$ & Status in original indication \\
\hline AZ-1 & Trk1 & 0.6 & 10.4 & Stopped after GLP toxicity \\
AZ-2 & JAK2 & 0.1 & 2.0 & Stopped after GLP toxicity \\
AZ-3 & FAR & 1.1 & 11.7 & Stopped after Phase II \\
AZ-4 & CDK2 & 1.2 & 11.3 & Stopped after GLP toxicity \\
AZ-5 & Aurora & 0.4 & 17.1 & Stopped after GLP toxicity \\
& kinase 1 & & \\
AZ-6 & CHK1 & 0.4 & 0.3 & Stopped after GLP toxicity \\
\hline
\end{tabular}

GLP, good laboratory practice.

Study performed by AstraZeneca.

SYBR $^{\oplus}$ I fluorescence assay for activity against $P$. falciparum strain NF54 and cytotoxicity assay against HepG2.

\section{Plasmodium falciparum huSCID mouse model}

The in vivo efficacy of four compounds was determined against $P$. falciparum in the humanized mouse model (Table 6, Figure 3). Two of these (UK-112,214 and lestaurtinib) were identified in screening and two (CEP1347 and PSC-833) were sourced additionally as a result of findings with related compounds during screening.

The most active agent tested was UK-112,214, a water soluble PAF-H1 inhibitor identified in the Pfizer STLAR screen (Figure 4A). UK-112,214 had an $\mathrm{ED}_{90}$ of $131.3 \mathrm{mg} / \mathrm{kg}$ (95\% CI 112.3, 156.7), oral exposure was good, and the pharmacokinetic profile appeared linear within the dosing range (Figure 4B, Table 7). Exposure data from UK-112,214-treated mice versus parasitaemia fitted a sigmoid function (coefficient of determination $\left.R^{2}=.996\right)$. The estimated $\mathrm{AUC}_{\mathrm{ED} 90}$ for UK-112,214 was $111.5 \mu \mathrm{g} \cdot \mathrm{h} \cdot \mathrm{mL}^{-1} \cdot$ day $^{-1}$ (95\% CI 106.6, 121.1) (Table 7). In this model, the $\mathrm{ED}_{90}$ or $\mathrm{AUC}_{\mathrm{ED} 90}$ mark the limit between $P$. falciparum net growth (at lower dose or exposure) or net clearance from peripheral blood (at higher doses or exposure). Therefore, in order to achieve net clearance of $P$. falciparum from peripheral blood of mice in two cycles of the parasite, a daily exposure higher than the $\mathrm{AUC}_{\mathrm{ED} 90}\left(111.5 \mu \mathrm{g} \cdot \mathrm{h} \cdot \mathrm{mL}^{-1} \cdot\right.$ day $\left.^{-1}\right)$ would be required. A qualitative analysis of the effect of treatment with $300 \mathrm{mg} / \mathrm{kg}$ UK-122,214 using microscopy and flow cytometry found parasites remaining in peripheral blood 48 hours after the start of treatment (Figure 5A). These showed cytoplasmic condensation, vacuolization of trophozoites and absence of mature schizonts. At 96 hours after the start of treatment some pycnotic parasites were also detected (Figure 5B). These results suggest that UK112,214 does not induce fast killing of $P$. falciparum in peripheral blood.

Lestaurtinib (CEP-701) is a protein kinase inhibitor thought to target fibroblast growth factor receptor 1 (FGFR1), fms-like tyrosine kinase 3 (FLT3), tyrosine kinase A (TrkA) and janus kinase 2 (Jak2). A related compound

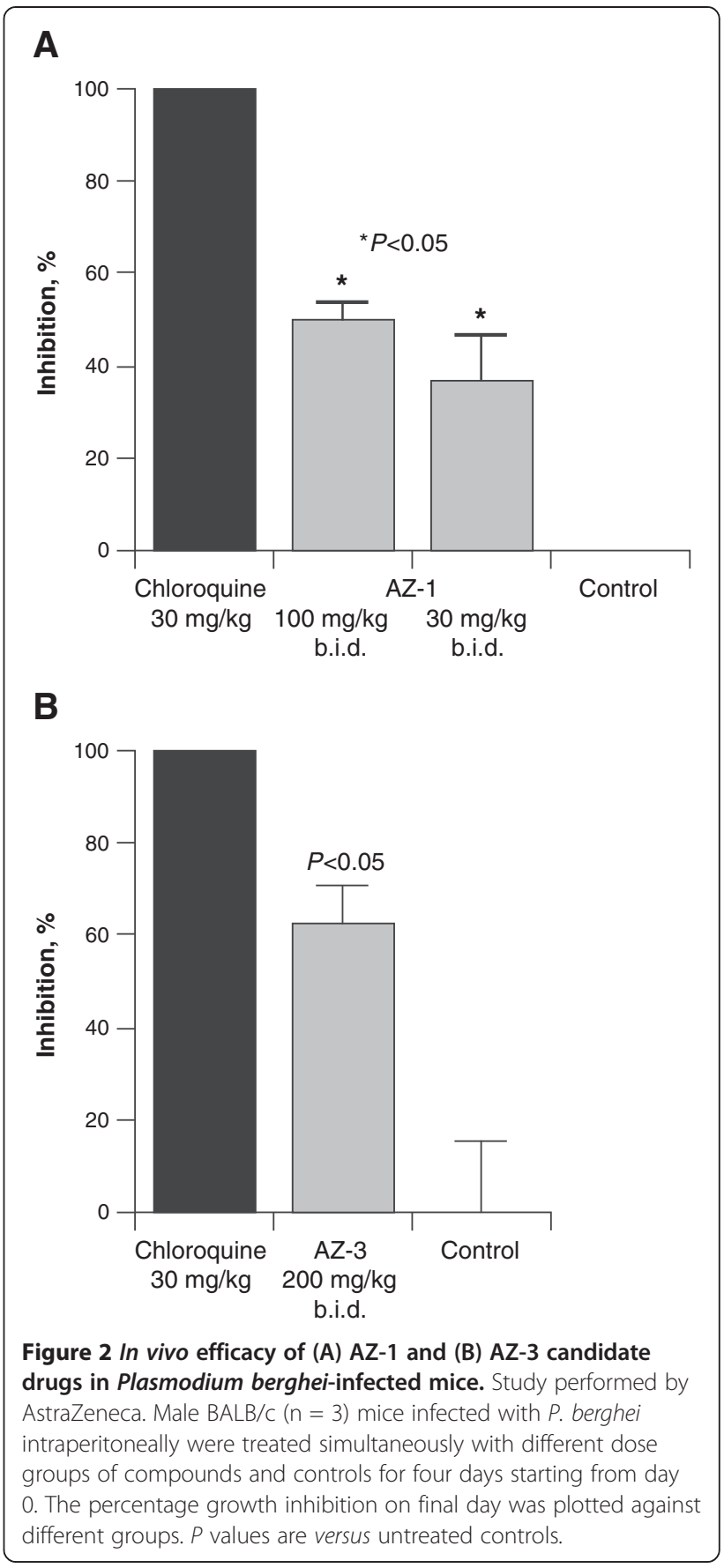

(CEP-1347) was also provided by Cephalon Inc for testing in the model. These compounds were tested up to the maximum tolerated dose. Although there was a trend for reduced parasitaemia in mice treated with these compounds, the reduction did not reach statistical significance and $\mathrm{ED}_{90}$ or $\mathrm{AUC}_{\mathrm{ED} 90}$ could not be estimated (Figure 6). For CEP-1347 in the P. falciparum-infected mice, the pharmacokinetics after subcutaneous administration in the studied dose range did not appear to be linear, with similar values of $C_{\max }$ and $A U C_{(0-t)}$ after the administration of 
Table 6 Therapeutic efficacy of test compounds against Plasmodium falciparum Pf3D7 ${ }^{0087 / N 9}$ in a humanized mouse model

\begin{tabular}{|c|c|c|c|c|}
\hline Compound & Target dose $(\mathrm{mg} / \mathrm{kg}) /$ route & $\mathrm{ED}_{50}(\mathrm{mg} / \mathrm{kg})$ & $\mathrm{ED}_{90}(\mathrm{mg} / \mathrm{kg})$ & $\mathrm{AUC}_{\mathrm{ED} 90}\left(\mu \mathrm{g} \cdot \mathrm{h} \cdot \mathrm{mL}^{-1} \cdot \mathrm{day}^{-1}\right)$ \\
\hline UK-112,214 & 100,300 po & $80.1(99.8,55.1)$ & $131.3(112.3,156.7)$ & $111.5(106.6,121.1)$ \\
\hline CEP-701 & $10,30 \mathrm{sc}$ & NC & NC & NC \\
\hline CEP-1347 & $10,30 \mathrm{sc}$ & NC & NC & NC \\
\hline PSC-833 & $50,100,200 \mathrm{po}$ & - & $>200$ & $>17.33$ \\
\hline
\end{tabular}

$\mathrm{ED}_{50}$ and $\mathrm{ED}_{90}$ values are shown as the mean $(95 \% \mathrm{Cl})$. Data was calculated to three decimal places.

$\mathrm{NC}$, not calculated as the percent reduction in parasitaemia was not significantly different from that of the control animals receiving vehicle only.

sc, subcutaneous; po, oral administration.

Study performed by GlaxoSmithKline.

the two selected doses (Table 7). The experimental doses of lestaurtinib were lower than the target ones, but again, non-linear pharmacokinetic behaviour was observed (Table 7). Note that preclinical studies in mouse cancer models had shown efficacy at exposures similar to those that were achieved in the current study [45].
An additional compound, PSC-833 (valspodar), was tested. This is a non-immunosuppressive cyclosporin derivative developed primarily as a p-glycoprotein inhibitor. As cyclosporin had been active during in vitro screening against $P$. falciparum but cannot be considered because of its immunosuppressive properties, valspodar<smiles>CC(C)Oc1cc(Nc2nc(N[C@@H](C)c3ccc(F)cn3)ncc2Cl)n[nH]1</smiles>

AZ-1 or AZD1332<smiles>Cc1nc2cnccc2n1-c1ccc(C(=O)N2CCC(=C3c4ccc(Cl)cc4CCc4cccnc43)CC2)cc1</smiles>

UK-112,214

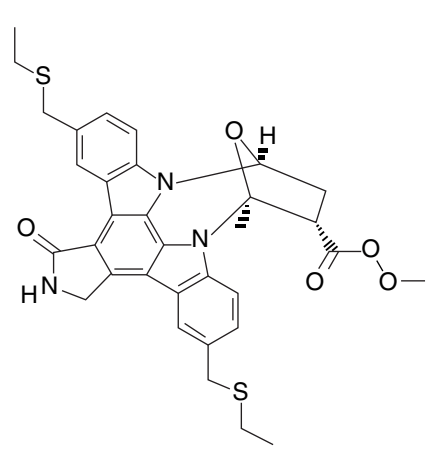

CEP-1347<smiles>C=C(N[C@@H](CCSC)C(=O)OC(C)C)c1cc(NC[C@H]2CC[C@H](SC(=O)c3cccnc3)N2)ccc1CCF</smiles>

AZ-3 or AZD3409

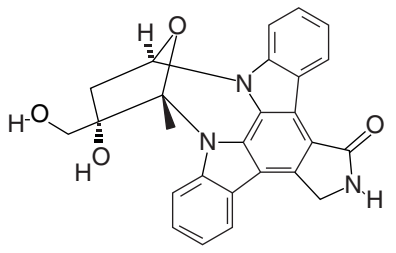

Lestaurtinib (CEP-701)

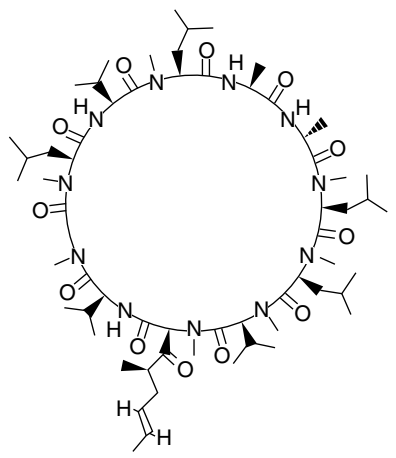

PSC833 (valspodar)

Figure 3 Structure of four compounds tested in the Plasmodium falciparum huSCID mouse model and two compounds tested in Plasmodium berghei-infected mice. 

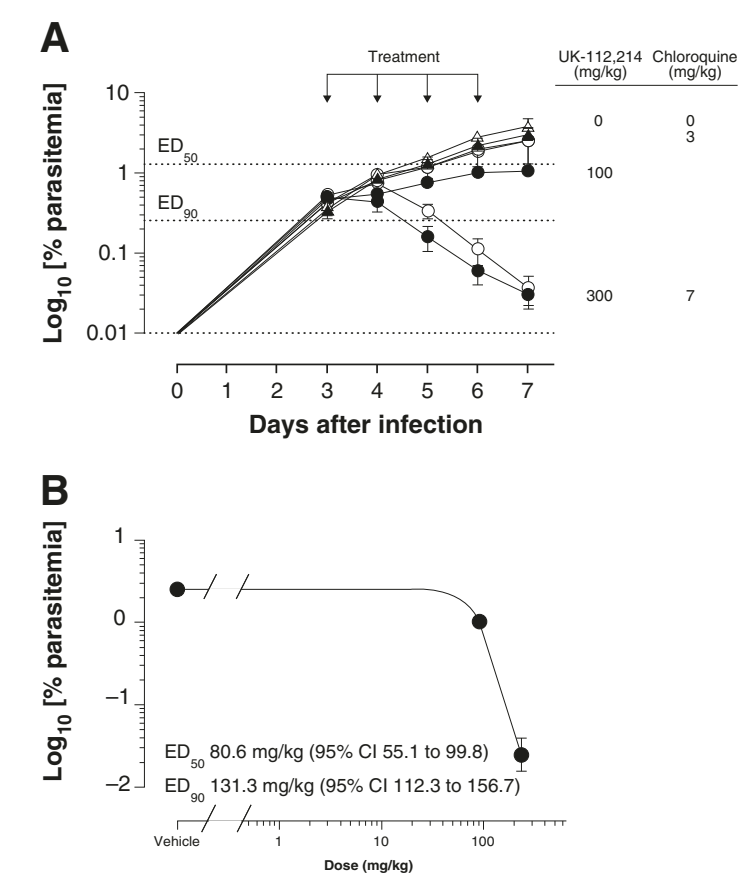

Figure 4 Therapeutic efficacy of UK-112,214 against Plasmodium falciparum Pf3D7 ${ }^{0087 / N 9}$. A) Parasitaemia in peripheral blood of mice obtained from day 3 to day 7 after infection for UK-112,214 (closed circles) or chloroquine (open circles). Data are presented as mean of three mice \pm SE for $\log _{10}[\%$ parasitaemia]. Data for vehicle-treated animals are denoted by triangles; B) Dose-response relationship for $\log _{10}[\%$ parasitaemia] at day 7 after infection. Study performed by GlaxoSmithKline.

was considered a potential substitute for addressing the cyclosporin target. This compound was sourced from Novartis AG, and although it had completed Phase III studies as an oncology drug, it had been discontinued for lack of efficacy. Valspodar did not significantly inhibit
P. falciparum parasitaemia in vivo $\left(\mathrm{ED}_{90}>200 \mathrm{mg} / \mathrm{kg}\right)$ (Table 6). The oral pharmacokinetics in the dose range studied was non-linear, with similar values of $\mathrm{AUC}_{(0-\mathrm{t})}$ for both dose levels (100 and $200 \mathrm{mg} / \mathrm{kg}$ ) (Table 7).

In programmes that are currently being conducted in collaboration with or supported by MMV, a significant in vivo potency in the humanized mouse model is considered to be lower than $20 \mathrm{mg} / \mathrm{kg}$. Therefore, none of the drugs tested met the criteria for further development.

\section{Discussion}

Although a large number of approved, investigational and discontinued drugs were evaluated in this project, none of the compounds identified with antiplasmodial activity met the candidate selection criteria warranting further development. From the approximately 3,800 compounds that were tested by SJCRH, there were 24 with $\mathrm{EC}_{50}$ values $<1 \mu \mathrm{M}$ against $P$. falciparum - a hit rate of about $0.6 \%$, which is similar to that obtained when testing sets of random pharmaceutical diversity. Within the unregistered compound sets of GSK, Pfizer and AZ, 15 of the 338 compounds tested showed significant in vitro activity - a hit rate of $4.4 \%$. This higher hit rate in the unregistered compound sets probably reflects the greater diversity of bio-activity the SJCRH compound set. The unregistered compounds reflect the focus of recent pharmaceutical development in the companies concerned in anti-proliferative, anti-infective and antiinflammatory disease, areas likely to have biological overlap with processes in the malaria parasite.

Encouragingly, it is clear that a number of different targets in the malaria parasite can be addressed by existing drugs. For example, several protein kinase inhibitors showed in vitro activity against $P$. falciparum in this study (bosutinib, midostaurin, lestaurtinib, lapatinib, sorafenib,

Table 7 Pharmacokinetics of test compounds in Plasmodium falciparum-infected humanized mice

\begin{tabular}{|c|c|c|c|c|c|}
\hline Compound & Target dose $(\mathrm{mg} / \mathrm{kg})$ & $C_{\max }(\mu \mathrm{g} / \mathrm{mL})$ & $t_{\max }(h)$ & $A U C_{(0-t)}(\mu \mathrm{g} \cdot \mathrm{h} \cdot \mathrm{mL})$ & DNAUC $_{(0-t)}\left(\mu \mathrm{g} \cdot \mathrm{h} \cdot \mathrm{mL}^{-1} \cdot\right.$ day $\left.^{-1}\right)$ \\
\hline UK-112,214 & 100 & $8.61(0.4)$ & $4.0(1.7)$ & $72.1(2.7)$ & $0.859(0.32)$ \\
\hline UK-112,214 & 300 & $17.6(6.4)$ & $3.3(4.0)$ & $231(101)$ & $1.03(0.45)$ \\
\hline CEP- $701^{a}$ & 10 & $0.63(0.079)$ & $0.78(0.38)$ & $2.8(0.46)$ & $0.44(0.072)$ \\
\hline CEP-701 ${ }^{a}$ & 30 & $2.8(0.84)$ & $4.0(1.7)$ & $23.8(6.8)$ & $1.6(0.47)$ \\
\hline CEP-1347 ${ }^{\mathrm{b}}$ & 10 & $0.83(0.44)$ & $4.8(4.0)$ & $8.1(1.8)$ & $0.98(0.22)$ \\
\hline CEP-1347 ${ }^{b}$ & 30 & $0.73(0.20)$ & $6.0(\mathrm{NA})$ & $9.9(2.1)$ & $0.45(0.092)$ \\
\hline PSC-833 & 50 & $1.39(0.20)$ & $3.30(1.2)$ & $12.90(2.97)$ & $0.36(0.082)$ \\
\hline PSC-833 & 100 & $1.01(0.53)$ & $5.33(3.05)$ & $12.26(4.25)$ & $0.13(0.04)$ \\
\hline PSC-833 & 200 & $0.91(0.47)$ & $2(0)$ & $13.05(6.05)$ & $0.065(0.03)$ \\
\hline
\end{tabular}

NA, not available; DNAUC, dose-normalized value of $\mathrm{AUC}_{(0-\mathrm{t})}$.

Values are the mean (SD). Pharmacokinetics were estimated in whole blood after oral UK-112,214 and PSC-833 or subcutaneous CEP-701 and CEP-1347 administration to $P$. falciparum-infected humanized mice.

${ }^{a}$ Note that the experimental doses were 6.4 and $15.0 \mathrm{mg} / \mathrm{kg}$ (versus target doses of 10 and $30 \mathrm{mg} / \mathrm{kg}$, respectively).

${ }^{\mathrm{b}}$ Note that the experimental doses were 8.3 and $22.0 \mathrm{mg} / \mathrm{kg}$ (versus target doses of $10 \mathrm{and} 30 \mathrm{mg} / \mathrm{kg}$, respectively).

${ }^{c}$ Note that the experimental dose was $36 \mathrm{mg} / \mathrm{kg}$ (versus target dose of $50 \mathrm{mg} / \mathrm{kg}$ ).

Study performed by GlaxoSmithKline. 


\section{A) Day 5, $48 \mathrm{~h}$ after the first dose} Vehicle
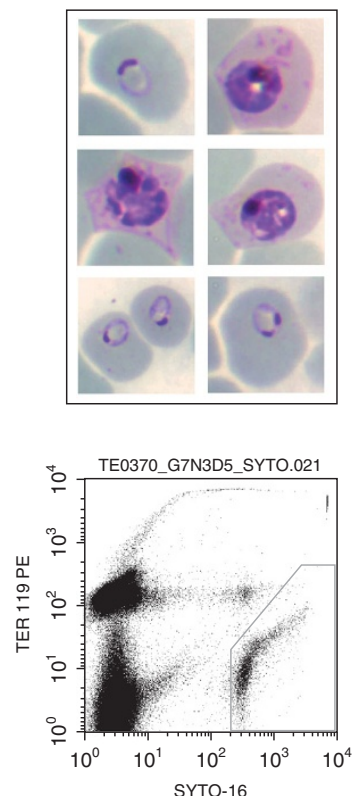

UK-112,214

$(100 \mathrm{mg} / \mathrm{kg})$
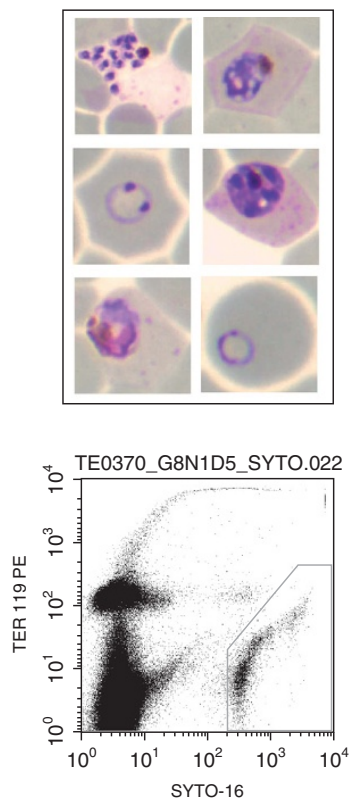

B) Day 7, $96 \mathrm{~h}$ after the first dose Vehicle
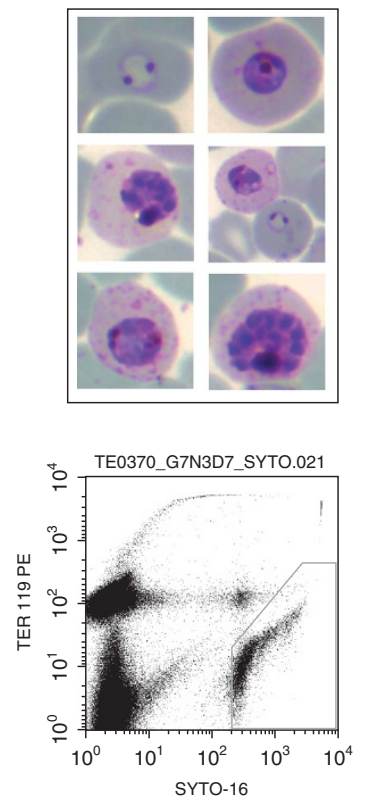

UK-112,214 $(100 \mathrm{mg} / \mathrm{kg})$
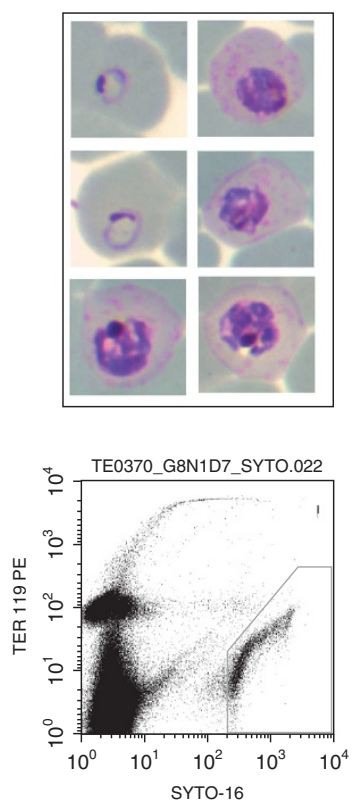

UK-112,214

$(300 \mathrm{mg} / \mathrm{kg})$
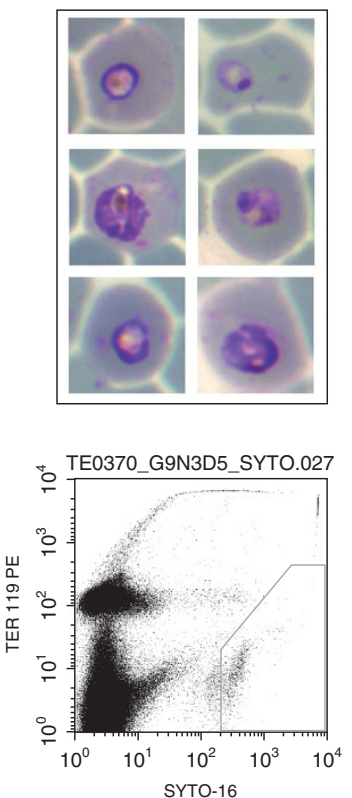

Figure 5 The effect of UK-112,214 treatment on Plasmodium falciparum Pf3D70087/N9 in vivo at (A) Day 5 and (B) Day 7. Photomicrographs of peripheral blood smears stained with Giemsa. Lower panels show flow cytometry dot plots from samples of peripheral blood stained with TER-119Phycoerythrine (marker of murine erythrocytes) and SYTO-16 (nucleic acid dye). Dots inside the polygonal region represent $P$. falciparum-infected human erythrocytes. Study performed by GlaxoSmithKline.

and CE-245677). These compounds were of particular interest as they are essential throughout all stages of the Plasmodium spp. lifecycle [40,41]. Many protein kinase inhibitors have been registered or investigated, primarily for the treatment of cancer, although these drugs have known toxicities that have discouraged their use in 


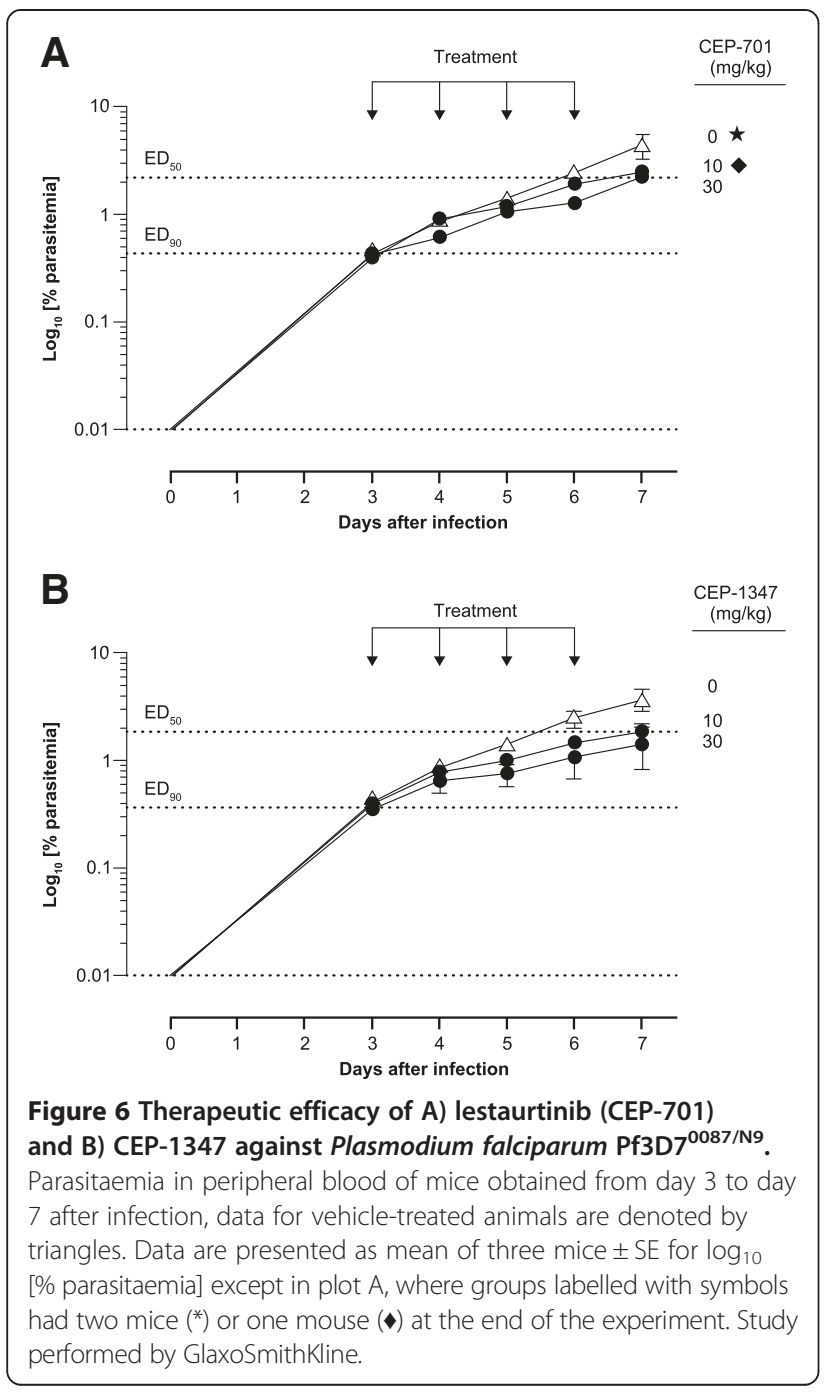

malaria. Antiretroviral protease inhibitors were also of interest and tested in this study, though they had relatively poor in vitro activity. Previous data showed moderate in vitro activity of saquinavir, nevirapine, ritonavir, nelfinavir, amprenavir, and indinavir at clinically relevant concentrations [46]. However, a recent clinical study in HIV-infected women from malaria-endemic regions of sub-Saharan Africa showed no effect of antiretroviral treatment on the incidence of malaria [47].

Among the licensed products that were active in vitro, none of the compounds were progressed to the in vivo model, mainly because of their unfavourable pharmacokinetic and/or safety profile for use as an oral anti-malarial. However, the scope of this study did not include speculation about the clinical safety and pharmacokinetics that might be discovered should clinical studies in malaria be conducted. In fact, a number of these compounds have been investigated further in malaria. Methotrexate has good activity against $P$. falciparum and Plasmodium vivax in vitro, although poor activity in vivo against murine malaria species [48-50]. The assumed toxicity of methotrexate and other anticancer drugs when used in short-course, low-dose therapy has been questioned [51]. However, a recent clinical study of methotrexate in healthy volunteers failed to achieve sufficient drug exposures for effective malaria therapy [52]. Methylene blue has also been investigated clinically for malaria, although it is slow acting and there are potential haemolytic effects of this compound in glucose-6-phosphate dehydrogenase-deficient individuals [53-56]. Bortezomib has confirmed in vitro activity against $P$. falciparum [57], although clinically its effect as an immunosuppressant probably precludes its use in malaria. Similarly, although cyclosporin A has shown good efficacy in a murine mouse model [58], its immunosuppressive effect prevents its repositioning as an anti-malarial.

Of the non-marketed products, four were selected from the test sets for in vivo evaluation (AZ-1, AZ-3, UK-112,214, and lestaurtinib) and two further drugs were sourced directly from their respective patent owners, CEP-1347 from Cephalon Inc and PSC833 (valspodar) from Novartis Inc. Of these six compounds, only UK112,214 showed significant activity in vivo. UK-112,214 is a water soluble PAF-H1 inhibitor targeted for use in allergic inflammatory conditions, such as allergic rhinitis. This is perhaps an unexpected target as clinical studies of the role of PAF in the most severe form of malaria, cerebral malaria, have been inconclusive [59]. However, astemizole, identified as a promising compound for repositioning in a previously reported study, is also a PAF-H1 inhibitor [22]. Of interest is that both UK-112,214 and astemizole have chemical structures related to known anti-malarial drugs of the 4-aminoquinoline class (Figures 3 and 7) and do not, therefore, represent a new class of anti-malarial agent. Astemizole was withdrawn because of cardiovascular adverse events, specifically prolongation of the QT interval caused by potent inhibition of hERG potassium channels [60]. The relative potential for cardiovascular adverse events with UK-112,214 is so far unreported, but an independently run hERG assay suggests it may too have a cardiac liability ( $\mathrm{hERG}=2.8 \mu \mathrm{M}$ ). The rate of $P$. falciparum parasite killing with UK-112,214 was slow, though it could potentially have utility as a combination therapy for the treatment of asexual P. falciparum should sufficient human exposure levels be achieved. Unfortunately, there are no human pharmacokinetic data on this compound in the public domain, but single-dose pharmacokinetic data provided by Pfizer indicate that UK-112,214 at doses from $10 \mathrm{mg}$ to $480 \mathrm{mg}$ resulted in $\mathrm{C}_{\max }$ values from 14 to $4145 \mathrm{ng} / \mathrm{ml}$.

Safety is the greatest impediment to the repositioning of existing drugs to treat malaria. Anti-malarial drugs are taken in possibly many millions of doses every year. Most importantly, an anti-malarial must be safe in children 


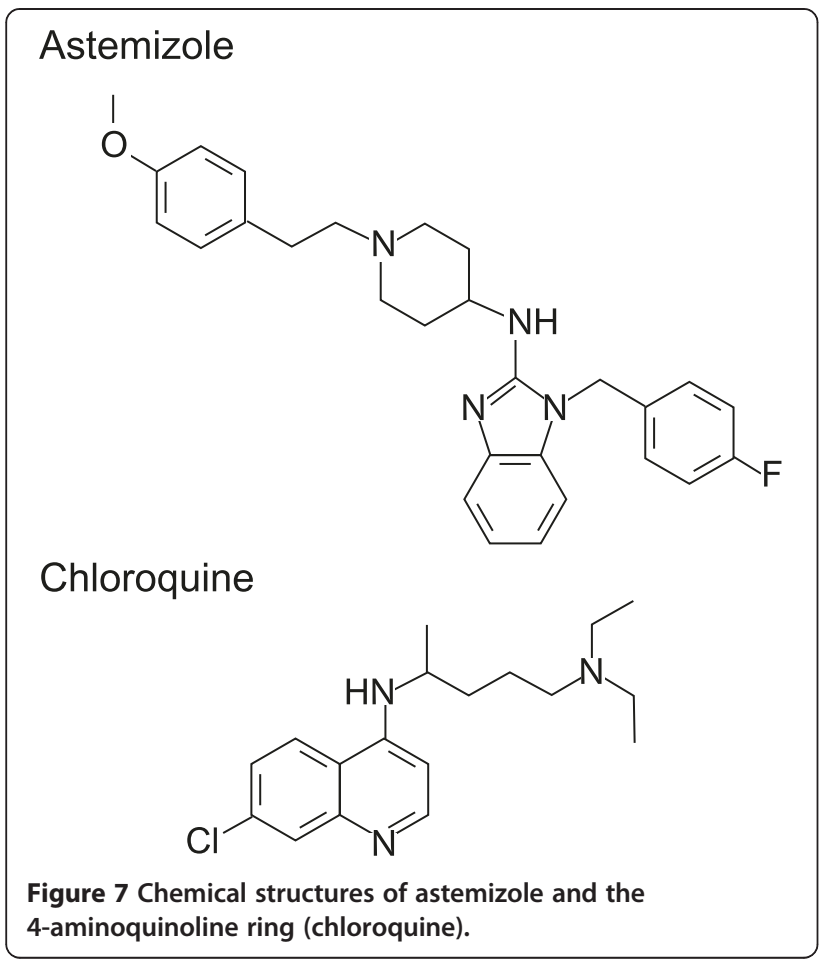

and pregnant women as these groups are most severely affected by the disease. Supply to the patient is often unregulated, self-medication is common and medical resources may be limited. Thus, patients may not be monitored for adverse events or be able to access medical care should these occur.

To achieve the required therapeutic window for an antimalarial drug, it should have good oral bio-availability, potent activity against the parasite and a high specificity for perturbing parasite metabolic and biochemical processes versus those of the host, ie, few and mild adverse events. These requirements are challenging, particularly for drugs that have been developed to affect human disease processes. In general, unless a drug demonstrates efficacy in malaria at a lower dose than in the 'parent' indication, the required therapeutic window cannot be achieved. Thus, repositioning of clinical compounds would seem most appropriate when the new use has a higher tolerance of potential safety signals, such as from malaria to cancer chemotherapy rather than vice versa.

In fact, anti-malarial drugs have been successfully repositioned into other therapeutic areas. Classically, hydroxyl chloroquine has been used to treat inflammatory conditions such as systemic lupus erythematosus, lupus nephritis and rheumatoid arthritis [61], and may also have utility in other auto-immune diseases [62]. More recently, investigations have been initiated into the use of anti-malarial drugs in cancer, for example, for the sensitization of tumours to enhance the response to conventional treatments $[63,64]$. Schistosomiasis is another indication that is being examined [65]. In particular, artemisinins appear to have many potential uses in diverse indications [66].

\section{Conclusions}

In recent years, repositioning of existing drug therapy has been suggested as a fast track to developing new anti-malarial medicines $[51,67,68]$. Studies such as this are necessary in the continuing efforts to explore all potential routes in the search for new effective medicines against this devastating disease. However, the drugs tested in this study did not approach the efficacy requirements for progression or had known safety issues preventing their use in malaria. Thus, it is becoming evident that the development of new drugs for the treatment of uncomplicated $P$. falciparum infection will probably require the design of molecules specifically targeted at the parasite and pharmacokinetically optimized to provide a sufficient margin of safety.

\section{Additional file}

Additional file 1: Expanded methods for in vitro assays.

\section{Competing interests}

TP, JM and TW are employees of Medicines for Malaria Venture. $J \mathrm{~L}$ is a former employee of Medicines for Malaria Venture. FJG-B, IA-B and SF-B are employees of GlaxoSmithKline PIc. SB is an employee of AstraZeneca. PV, BB and NR are former employees of AstraZeneca. TP is a former employee of Pfizer Inc. The remaining authors declare no competing interests.

\section{Authors' contributions}

TW generated the study concept. TW, JL and JM planned and coordinated the study. FJG-B, IA-B, JC, MC, SF-B, TP, PV, BB, NR, SB, SD, VA, and RKG were involved in data acquisition and data analysis. RKG provided expert advice on the in vitro screening strategy. All authors contributed to the paper and read and approved the final version submitted.

\section{Acknowledgements}

Thanks to Steve Trusko at Cephalon Inc, West Chester, PA, USA for providing compounds for testing. Thanks to Thierry Diagana at Novartis for providing PSC-833 compound for testing at GSK Tres Cantos. We thank the staff at MMV for the critical discussion and contributions throughout the project and the funding organizations for their support of MMV. RKG, WAG and JAC acknowledge the financial support of the American Lebanese Syrian Associated Charities (ALSAC) and NIH (Al075517 and Al090662). The authors are indebted to María Belén Jiménez-Díaz, Sara Viera, Helen Garuti, Noemí Magán Marchal, Vanesa Gómez, Teresa Mulet, Javier Ibáñez, María Santos Martínez, Leticia Huertas, Maria Jose Lafuente, Sara Prats, and Jaume Vidal at GSK for performing the in vivo experiments in P. falciparum-humanized mouse model. We thank Dr Leonard D Shultz and The Jackson Laboratory for providing access to NOD-scidll-2RY null mice through their collaboration with GlaxoSmithKline-Tres Cantos Medicines Development Campus. Thanks to Achyut Sinha, Bala Subramanian, Suresh Solapure, the DMPK and compound management teams at AstraZeneca for their various invaluable contributions to this project. Naomi Richardson of Magenta Communications Ltd provided writing and editorial assistance on this paper and was funded by Medicines for Malaria Venture.

\section{Funding}

This work was supported by the Medicines Malaria Venture, St Jude Children's Research Hospital, GlaxoSmithKline Plc and Pfizer Inc. 


\section{Author details}

'Medicines for Malaria Venture (MMV), PO Box 1826, 20 rte de Pré-Bois, 1215, Geneva 15, Switzerland. 2Diseases of the Developing World Medicines Development Campus, GlaxoSmithKline, Tres Cantos, Madrid, Spain. ${ }^{3}$ Department of Chemical Biology and Therapeutics, St Jude Children's Research Hospital, Memphis, TN, USA. Independent Consultant, Canterbury, UK. ${ }^{5}$ AstraZeneca India Pvt Ltd, Bellary Road, Hebbal, Bangalore, India. ${ }^{6}$ Discovery Biology, Eskitis Institute for Drug Discovery, Griffith University, Nathan, Australia.

\section{Received: 5 February 2014 Accepted: 23 March 2014}

Published: 14 April 2014

\section{References}

1. World Health Organization: World Malaria Report 2011; http:/www.who.int/ malaria/world_malaria_report_2011/en/.

2. World Health Organization: Global Malaria Control and Elimination: report of a technical review; http://whqlibdoc.who.int/publications/2008/9789241596756_ eng.pdf.

3. Roberts $L$, Enserink M: Malaria. Did they really say eradication? Science 2007, 318:1544-1545.

4. Wells TN, Alonso PL, Gutteridge WE: New medicines to improve control and contribute to the eradication of malaria. Nat Rev Drug Discov 2009 8:879-891.

5. malERA Consultative Group on Drugs: A research agenda for malaria eradication: drugs. PLoS Med 2011, 8:e1000402.

6. World Health Organization: Global report on antimalarial drug efficacy and drug resistance: 2000-2010; http://whalibdoc.who.int/publications/2010/ 9789241500470_eng.pdf.

7. White NJ: Artemisinin resistance - the clock is ticking. Lancet 2010, 376:2051-2052.

8. Guiguemde WA, Shelat AA, Garcia-Bustos JF, Diagana TT, Gamo FJ, Guy RK: Global phenotypic screening for antimalarials. Chem Biol 2012. 19:116-129.

9. Gamo FJ, Sanz LM, Vidal J, de Cozar C, Alvarez E, Lavandera JL, Vanderwall $D E$, Green DV, Kumar V, Hasan S, Brown JR, Peishoff CE, Cardon LR, Garcia-Bustos JF: Thousands of chemical starting points for antimalarial lead identification. Nature 2010, 465:305-310.

10. Guiguemde WA, Shelat AA, Bouck D, Duffy S, Crowther GJ, Davis PH Smithson DC, Connelly M, Clark J, Zhu F, Jimenez-Diaz MB, Martinez MS, Wilson EB, Tripathi AK, Gut J, Sharlow ER, Bathurst I, El Mazouni F, Fowble JW, Forquer I, McGinley PL, Castro S, Angulo-Barturen I, Ferrer S, Rosenthal PJ, Derisi JL, Sullivan DJ, Lazo JS, Roos DS, Riscoe MK et al: Chemical genetics of Plasmodium falciparum. Nature 2010, 465:311-315.

11. The European Bioinformatics Institute; http://www.ebi.ac.uk/.

12. Anthony MP, Burrows JN, Duparc S, Moehrle J, Wells TN: The global pipeline of new medicines for the control and elimination of malaria. Malar J 2012, 11:316

13. Rottmann M, MCNamara C, Yeung BK, Lee MC, Zou B, Russell B, Seitz P, Plouffe DM, Dharia NV, Tan J, Cohen SB, Spencer KR, Gonzalez-Paez GE, Lakshminarayana SB, Goh A, Suwanarusk R, Jegla T, Schmitt EK, Beck HP, Brun R, Nosten F, Renia L, Dartois V, Keller TH, Fidock DA, Winzeler EA, Diagana TT: Spiroindolones, a potent compound class for the treatment of malaria. Science 2010, 329:1175-1180.

14. Cavalla D: APT drug R\&D: the right active ingredient in the right presentation for the right therapeutic use. Nat Rev Drug Discov 2009, 8:849-853.

15. Jin G, Fu C, Zhao H, Cui K, Chang J, Wong ST: A novel method of transcriptional response analysis to facilitate drug repositioning for cancer therapy. Cancer Res 2012, 72:33-44.

16. Sardana D, Zhu C, Zhang M, Gudivada RC, Yang L, Jegga AG: Drug repositioning for orphan diseases. Brief Bioinform 2011, 12:346-356.

17. Lougheed KE, Taylor DL, Osborne SA, Bryans JS, Buxton RS: New anti-tuberculosis agents amongst known drugs. Tuberculosis (Edinb) 2009, 89:364-370.

18. Abdulla MH, Ruelas DS, Wolff B, Snedecor J, Lim KC, Xu F, Renslo AR, Williams J, McKerrow JH, Caffrey CR: Drug discovery for schistosomiasis: hit and lead compounds identified in a library of known drugs by medium-throughput phenotypic screening. PLoS Negl Trop Dis 2009, 3:e478.
19. Gloeckner C, Garner AL, Mersha F, Oksov Y, Tricoche N, Eubanks LM, Lustigman S, Kaufmann GF, Janda KD: Repositioning of an existing drug for the neglected tropical disease onchocerciasis. Proc Natl Acad Sci U S A 2010, 107:3424-3429.

20. Jennings FW, Urquhart GM: The use of the 2 substituted 5-nitroimidazole, Fexinidazole (Hoe 239) in the treatment of chronic T. brucei infections in mice. $Z$ Parasitenkd 1983, 69:577-581.

21. Torreele E, Bourdin Trunz B, Tweats D, Kaiser M, Brun R, Mazue G, Bray MA, Pecoul B: Fexinidazole-a new oral nitroimidazole drug candidate entering clinical development for the treatment of sleeping sickness. PLoS Negl Trop Dis, 4:e923. http://www.ncbi.nlm.nih.gov/pubmed/21200426.

22. Chong CR, Chen X, Shi L, Liu JO, Sullivan DJ Jr: A clinical drug library screen identifies astemizole as an antimalarial agent. Nat Chem Biol 2006, 2:415-416.

23. Buchholz K, Burke TA, Williamson KC, Wiegand RC, Wirth DF, Marti M: A high-throughput screen targeting malaria transmission stages opens new avenues for drug development. J Infect Dis 2011, 203:1445-1453.

24. da Cruz FP, Martin C, Buchholz K, Lafuente-Monasterio MJ, Rodrigues T, Sonnichsen B, Moreira R, Gamo FJ, Marti M, Mota MM, Hannus M, Prudencio M: Drug screen targeted at Plasmodium liver stages identifies a potent multistage antimalarial drug. J Infect Dis 2012, 205:1278-1286.

25. Medicines for Malaria Venture: Target Product Proposal 1; Available at: http://www.mmv.org/sites/default/files/uploads/docs/essential_info_for_ scientists/TCPs_and_TPPs/TPP1_with_figures.pdf.

26. Medicines for Malaria Venture: Target Product Proposal 2; Available at:http:// www.mmv.org/sites/default/files/uploads/docs/essential_info_for_scientists/ TCPs_and_TPPs/TPP2.pdf.

27. Bennett TN, Paguio M, Gligorijevic B, Seudieu C, Kosar AD, Davidson E, Roepe PD: Novel, rapid, and inexpensive cell-based quantification of antimalarial drug efficacy. Antimicrob Agents Chemother 2004, 48:1807-1810

28. Trager W, Jensen JB: Human malaria parasites in continuous culture. Science 1976, 193:673-675.

29. Smilkstein M, Sriwilaijaroen N, Kelly JX, Wilairat P, Riscoe M: Simple and inexpensive fluorescence-based technique for high-throughput antimalarial drug screening. Antimicrob Agents Chemother 2004, 48:1803-1806.

30. Chulay JD, Haynes JD, Diggs CL: Plasmodium falciparum: assessment of in vitro growth by [3H] hypoxanthine incorporation. Exp Parasitol 1983, 55:138-146.

31. Desjardins RE, Canfield CJ, Haynes JD, Chulay JD: Quantitative assessment of antimalarial activity in vitro by a semiautomated microdilution technique. Antimicrob Agents Chemother 1979, 16:710-718.

32. Malaria Research and Reference Reagent Resource Center (MR4); http://www.mr4.org.

33. Duffy S, Avery VM: Development and optimization of a novel 384-well anti-malarial imaging assay validated for high-throughput screening. Am J Trop Med Hyg 2012, 86:84-92.

34. Peters W: Chemotherapy and drug resistance in malaria (vol. 1). London: Academic Press; 1987.

35. Reddy J, Madishetti S, Vachaspati PR: Fast mouse PK (Fast PK): a rapid screening method to increase pharmacokinetic throughput in pre-clinical drug discovery. Eur J Pharm Sci 2012, 47:444-450.

36. Angulo-Barturen I, Jimenez-Diaz MB, Mulet T, Rullas J, Herreros E, Ferrer S, Jimenez E, Mendoza A, Regadera J, Rosenthal PJ, Bathurst I, Pompliano DL, Gomez De Las Heras F, Gargallo-Viola D: A murine model of falciparum-malaria by in vivo selection of competent strains in non-myelodepleted mice engrafted with human erythrocytes. PLoS One 2008, 3:e2252.

37. Jimenez-Diaz MB, Mulet T, Viera S, Gomez V, Garuti H, Ibanez J, Alvarez-Doval A, Shultz LD, Martinez A, Gargallo-Viola D, Angulo-Barturen I: Improved murine model of malaria using Plasmodium falciparum competent strains and non-myelodepleted NOD-scid IL2Rgnull mice engrafted with human erythrocytes. Antimicrob Agents Chemother 2009, 53:4533-4536.

38. Jimenez-Diaz MB, Mulet $T$, Gomez V, Viera S, Alvarez A, Garuti $H$, Vazquez Y, Fernandez A, Ibanez J, Jimenez M, Gargallo-Viola D, Angulo-Barturen I: Quantitative measurement of Plasmodium-infected erythrocytes in murine models of malaria by flow cytometry using bidimensional assessment of SYTO-16 fluorescence. Cytometry A 2009, 75:225-235. 
39. Nilsen A, LaCrue AN, White KL, Forquer IP, Cross RM, Marfurt J, Mather MW Delves MJ, Shackleford DM, Saenz FE, Morrisey JM, Steuten J, Mutka T, Li Y, Wirjanata G, Ryan E, Duffy S, Kelly JX, Sebayang BF, Zeeman AM, Noviyanti R, Sinden RE, Kocken CH, Price RN, Avery VM, Angulo-Barturen I, Jimenez-Diaz MB, Ferrer S, Herreros E, Sanz LM et al: Quinolone-3-diarylethers: a new class of antimalarial drug. Sci Transl Med 2013, 5:177-137.

40. Doerig C: Protein kinases as targets for anti-parasitic chemotherapy. Biochim Biophys Acta 2004, 1697:155-168.

41. Zhang VM, Chavchich M, Waters NC: Targeting protein kinases in the malaria parasite: update of an antimalarial drug target. Curr Top Med Chem 2012, 12:456-472.

42. Weisman JL, Liou AP, Shelat AA, Cohen FE, Guy RK, DeRisi JL: Searching for new antimalarial therapeutics amongst known drugs. Chem Biol Drug Des 2006, 67:409-416.

43. Enders $\mathrm{GH}$ : Mammalian interphase $\mathrm{Cdks}$. Dispensable master regulators of the cell cycle. Genes Cancer 2012, 3:11-12.

44. Kollareddy M, Zheleva D, Dzubak P: Subhashchandra Brahmkshatriya P, Lepsik M, Hajduch M: Aurora kinase inhibitors: Progress towards the clinic. Invest New Drugs 2012, 30:2411-2432.

45. Hexner EO, Serdikoff C, Jan M, Swider CR, Robinson C, Yang S, Angeles T, Emerson SG, Carroll M, Ruggeri B, Dobrzanski P: Lestaurtinib (CEP701) is a JAK2 inhibitor that suppresses JAK2/STAT5 signaling and the proliferation of primary erythroid cells from patients with myeloproliferative disorders. Blood 2008, 111:5663-5671.

46. Skinner-Adams TS, McCarthy JS, Gardiner DL, Hilton PM, Andrews KT: Antiretrovirals as antimalarial agents. J Infect Dis 2004, 190:1998-2000.

47. Skinner-Adams TS, Butterworth AS, Porter KA, D'Amico R, Sawe F, Shaffer D, Siika A, Hosseinipour MC, Stringer E, Currier JS, Chipato T, Salata R, Lockman S, Eron JJ, Meshnick SR, McCarthy JS: The frequency of malaria is similar among women receiving either lopinavir/ritonavir or nevirapine-based antiretroviral treatment. PLoS One, 7:e34399.

48. Irungu B, Kiboi D, Langat B, Rukunga G, Wittlin S, Nzila A: Methotrexate and aminopterin lack in vivo antimalarial activity against murine malaria species. Exp Parasitol 2009, 123:118-121.

49. Imwong M, Russell B, Suwanarusk R, Nzila A, Leimanis ML, Sriprawat K, Kaewpongsri S, Phyo AP, Snounou G, Nosten F, Renia L: Methotrexate is highly potent against pyrimethamine-resistant Plasmodium vivax. J Infect Dis 2011, 203:207-210.

50. Dar O, Khan MS, Adagu I: The potential use of methotrexate in the treatment of falciparum malaria: in vitro assays against sensitive and multidrug-resistant falciparum strains. Jpn J Infect Dis 2008, 61:210-211.

51. Nzila A, Okombo J, Becker RP, Chilengi R, Lang T, Niehues T: Anticancer agents against malaria: time to revisit? Trends Parasitol 2010, 26:125-129.

52. Chilengi $R$, Juma $R$, Abdallah AM, Bashraheil $M$, Lodenyo $H$, Nyakundi $P$, Anabwani E, Salim A, Mwambingu G, Wenwa E, Jemutai J, Kipkeu C, Oyoo GO, Muchohi SN, Kokwaro G, Niehues T, Lang T, Nzila A: A phase I trial to evaluate the safety and pharmacokinetics of low-dose methotrexate as an anti-malarial drug in Kenyan adult healthy volunteers. Malar J 2011, $10: 63$.

53. Zoungrana A, Coulibaly B, Sie A, Walter-Sack I, Mockenhaupt FP, Kouyate B, Schirmer RH, Klose C, Mansmann U, Meissner P, Muller O: Safety and efficacy of methylene blue combined with artesunate or amodiaquine for uncomplicated falciparum malaria: a randomized controlled trial from Burkina Faso. PLoS One 2008, 3:e1630

54. Bountogo M, Zoungrana A, Coulibaly B, Klose C, Mansmann U, Mockenhaupt FP, Burhenne J, Mikus G, Walter-Sack I, Schirmer RH, Sie A, Meissner P, Muller O: Efficacy of methylene blue monotherapy in semi-immune adults with uncomplicated falciparum malaria: a controlled trial in Burkina Faso. Trop Med Int Health 2010, 15:713-717

55. Meissner PE, Mandi G, Coulibaly B, Witte S, Tapsoba T, Mansmann U, Rengelshausen J, Schiek W, Jahn A, Walter-Sack I, Mikus G, Burhenne J, Riedel KD, Schirmer RH, Kouyate B, Muller O: Methylene blue for malaria in Africa: results from a dose-finding study in combination with chloroquine. Malar J 2006, 5:84.

56. Muller O, Mockenhaupt FP, Marks B, Meissner P, Coulibaly B, Kuhnert R, Buchner H, Schirmer RH, Walter-Sack I, Sie A, Mansmann U: Haemolysis risk in methylene blue treatment of G6PD-sufficient and G6PD-deficient West-African children with uncomplicated falciparum malaria: a synopsis of four RCTs. Pharmacoepidemiol Drug Saf 2012, 22:376-385
57. Reynolds JM, El Bissati K, Brandenburg J, Gunzl A, Mamoun CB: Antimalarial activity of the anticancer and proteasome inhibitor bortezomib and its analog ZL3B. BMC Clin Pharmacol 2007, 7:13.

58. Bobbala D, Koka S, Lang C, Boini KM, Huber SM, Lang F: Effect of cyclosporine on parasitemia and survival of Plasmodium berghei infected mice. Biochem Biophys Res Commun 2008, 376:494-498.

59. Davis TM, Binh TQ, van Phuong N, Sturm M, St John A, Dyer JR, Anh TK: The metabolism of platelet-activating factor in severe and cerebral malaria. J Infect 1995, 31:181-188.

60. Zhou Z, Vorperian VR, Gong Q, Zhang S, January CT: Block of HERG potassium channels by the antihistamine astemizole and its metabolites desmethylastemizole and norastemizole. J Cardiovasc Electrophysiol 1999, 10:836-843.

61. Lee SJ, Silverman E, Bargman JM: The role of antimalarial agents in the treatment of SLE and lupus nephritis. Nat Rev Nephrol 2011, 7:718-729.

62. Ben-Zvi I, Kivity S, Langevitz P, Shoenfeld Y: Hydroxychloroquine: from malaria to autoimmunity. Clin Rev Allergy Immunol 2012, 42:145-153.

63. Solomon VR, Lee $\mathrm{H}$ : Chloroquine and its analogs: a new promise of an old drug for effective and safe cancer therapies. Eur J Pharmacol 2009, 625:220-233.

64. Crespo-Ortiz MP, Wei MQ: Antitumor activity of artemisinin and its derivatives: from a well-known antimalarial agent to a potential anticancer drug. J Biomed Biotechnol 2012, 2012:247597.

65. Keiser J, Utzinger J: Antimalarials in the treatment of schistosomiasis. Curr Pharm Des 2012, 18:3531-3538.

66. Njuguna NM, Ongarora DS, Chibale K: Artemisinin derivatives: a patent review (2006 - present). Expert Opin Ther Pat 2012, 22:1179-1203.

67. Nzila A, Ma Z, Chibale K: Drug repositioning in the treatment of malaria and TB. Future Med Chem 2011, 3:1413-1426.

68. Wu T, Nagle AS, Chatterjee AK: Road towards new antimalarials - overview of the strategies and their chemical progress. Curr Med Chem 2011, 18:853-871.

\section{doi:10.1186/1475-2875-13-143}

Cite this article as: Lotharius et al.: Repositioning: the fast track to new anti-malarial medicines? Malaria Journal 2014 13:143.

\section{Submit your next manuscript to BioMed Central and take full advantage of:}

- Convenient online submission

- Thorough peer review

- No space constraints or color figure charges

- Immediate publication on acceptance

- Inclusion in PubMed, CAS, Scopus and Google Scholar

- Research which is freely available for redistribution 